\title{
Photoreversible Birefringence Change of Diarylethene Single Crystals as Revealed by Change in Molecular Polarizability Anisotropy
}

Kohei Morimoto, Hajime Tsujioka, Daichi Kitagawa, Seiya Kobatake

\begin{tabular}{|c|c|}
\hline Citation & The Journal of Physical Chemistry A. 124(23); 4732-4741 \\
\hline Issue Date & 2020-05-20 \\
\hline Type & Journal Article \\
\hline Textversion & author \\
\hline $\begin{array}{l}\text { Supporting } \\
\text { Information }\end{array}$ & $\begin{array}{l}\text { Supporting Information is available on } \mathrm{https} \text { ://doi.org/10.1021/acs.jpca.0c02774. } \\
\text { - Preparation of thin crystal } 2 \mathrm{a} \text {; determination of the value of birefringence; and } \\
\text { polarizability anisotropy viewed from each crystal plane(PDF) }\end{array}$ \\
\hline Rights & $\begin{array}{l}\text { The following article has been accepted by The Journal of Physical Chemistry A. This } \\
\text { is the accepted manuscript version. Please cite only the published version. After it is } \\
\text { published, it will be found at https://doi.org/10.1021/acs.jpca.0c02774. }\end{array}$ \\
\hline DOI & 10.1021/acs.jpca.0c02774 \\
\hline
\end{tabular}

Self-Archiving by Author(s)

Placed on: Osaka City University Repository

Kohei Morimoto, Hajime Tsujioka, Daichi Kitagawa, Seiya Kobatake. (2020). Photoreversible Birefringence Change of Diarylethene Single Crystals as Revealed by Change in Molecular Polarizability Anisotropy. The Journal of Physical Chemistry A. 124, 4732-4741.

Doi:10.1021/acs.jpca.0c02774 


\section{Photoreversible Birefringence Change of Diarylethene Single Crystals as Revealed by Change in Molecular Polarizability Anisotropy}

Kohei Morimoto, Hajime Tsujioka, Daichi Kitagawa, and Seiya Kobatake*

Department of Applied Chemistry, Graduate School of Engineering, Osaka City University, 3-3-

138 Sugimoto, Sumiyoshi-ku, Osaka 558-8585, Japan.

*E-mail: kobatake@a-chem.eng.osaka-cu.ac.jp 
Abstract: Stimuli-responsive organic crystals represent a new frontier of material chemistry. Recently, we have reported photoreversible interference color change to multicolor in single crystals composed of a photochromic diarylethene derivative, 1,2-bis(2-ethyl-5-phenyl-3thienyl)perfluorocyclopentene (1a), accompanied by the photochromic reaction. The origin of the interference color change is due to the photoinduced birefringence change in the photoisomerization of diarylethenes. In this study, we newly found that single crystals composed of 1,2-bis(2,5-dimethyl3-thienyl)perfluorocyclopentene (2a) also exhibit a photoreversible interference color change. The birefringence value for crystal 2a increased with the photocyclization conversion, while that for crystal 1a decreased. The relationship between the photoinduced birefringence changes for crystals 1a and 2a and their molecular structures was discussed based on the change in the molecular polarizability anisotropy accompanied by the photochromic reaction. These results would provide not only new opportunities for the application of photochromic crystals but also useful strategies for the design of crystalline materials that exhibit the desired birefringence change. 


\section{Introduction}

Recently, organic crystals responding to external stimuli such as light, heat, electricity, gas, and force have been enthusiastically investigated because of their unique properties (e.g. mechanical effects, ${ }^{1-3}$ luminescent color change, ${ }^{4-8}$ self-healing, ${ }^{9-12}$ and gas absorption/release ${ }^{13}$ ). Photochromic diarylethene crystals have been investigated as the photoresponsive organic crystals having excellent photochromic properties such as high thermal stability of both isomers, high durability, high sensitivity, quick response, and high reactivity. ${ }^{14}$ Various physicochemical properties such as absorption spectra, refractive index, birefringence, permittivity, redox potential, fluorescence property, and electron spin in the crystal could be switched back and forth using UV and visible light.

Birefringence materials are essential to modulate the polarization of light. Thus, these are used in many application fields, such as the laser industry, optical communication, the polarimetry, and the scientific instrumentation. ${ }^{15-21}$ Organic crystals have birefringence due to molecular orientation. If birefringence in the crystal is switched by external stimuli, it should be expected as an innovative optical device like a switchable wavelength plate. Therefore, several groups have reported birefringence change in organic crystals by external stimulus. Horie et al. demonstrated that birefringence in the crystal composed of pseudorotaxane was reversibly changed by a phenyl ring rotation associated with a thermal phase transition. ${ }^{22,23}$ Moreover, Setaka et al. reported the birefringence change in crystalline molecular gyrotops. ${ }^{24-28}$ This is because a phenyl group encased in the three alkyl spokes was rotated. The higher the temperature of the crystal is, the faster the phenyl group rotates. Also, Diao et al. provided the interference color change accompanied by the birefringence change caused by a martensite phase transition of some organic semiconductor crystals. ${ }^{29-31}$ These birefringence modulations are induced by the change in temperatures such as heating and cooling processes. Moreover, Koshima and co-workers reported the photoreversible linear and circular birefringence change in the crystal of chiral salicylidenephenyletheylamines by employing the generalized high-accuracy universal polarimeter. ${ }^{32}$ In addition, very recently, we reported the photoreversible interference color change in single crystals composed of a diarylethene derivative, 1,2-bis(2-ethyl-5-phenyl-3-thienyl)perfluorocyclopentene (1a) (Scheme 1). ${ }^{33}$ The interference color change was originated from the birefringence change associated with the 
photochromic reaction, which was quite sensitive to the reaction. The birefringence modulation by light irradiation has advantages over that by temperature (heat) because no direct physical contact is required, and it is possible to control spatially and temporally. On the other hand, in these previous works about the birefringence change in organic crystals, the relationship between the birefringence change and molecular structure was not quantitatively investigated. To design the crystals that show the photoinduced birefringence change, it is necessary to find out the relationship between the birefringence change and the molecular structural change in detail.

In this study, we newly investigated the change in the photoreversible interference color of single crystals composed of a diarylethene derivative, 1,2-bis(2,5-dimethyl-3thienyl)perfluorocyclopentene (2a) (Scheme 1). We report the photoinduced birefringence change of crystal 2a associated with the photochromic reaction and the relationship between the change in birefringence and their molecular structures in comparison with crystal 1a. Our results may provide not only a new possibility for practical applications of photochromic crystals but also strategies for the design of molecular crystals that exhibit the desired birefringence change.

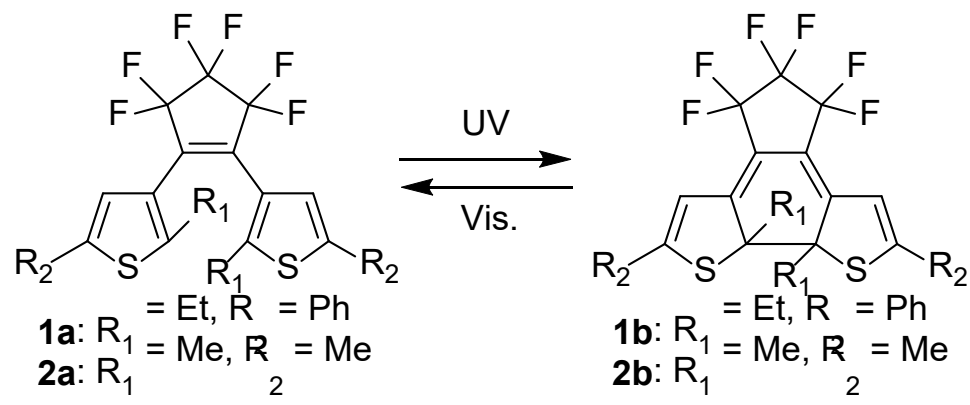

Scheme 1. Molecular structures of photochromic diarylethenes used in this work 


\section{Results and Discussion}

Interference Color Change for Crystal 2a. Thin single crystals of 2a with a thickness from a few to some tens of micrometers were successfully prepared by a sublimation method (Supporting Information). The crystal shape of $\mathbf{2 a}$ is shown in Figure 1a. The crystal system and space group of crystal $\mathbf{2 a}$ are monoclinic and $P 2_{1} / \mathrm{c}$, respectively. ${ }^{34}$ Crystal $\mathbf{2 a}$ consists of six faces that can be classified into two different types of faces. One is "Surface A" corresponding to (011), (011), (011), and (01) Miller planes. The other is "Surface B" corresponding to (100) and (100) Miller planes. ${ }^{34}$ Figure 1a and b show the optical microphotographs of single crystals of $\mathbf{2 a}$ well-developed on each surface and their molecular packings viewed from individual faces. Upon alternating irradiation with UV (365 nm) and visible light, both crystal surfaces changed color by the photochromic reaction between the colorless open-ring isomer (2a) and the colored closed-ring isomer (2b).

(a)
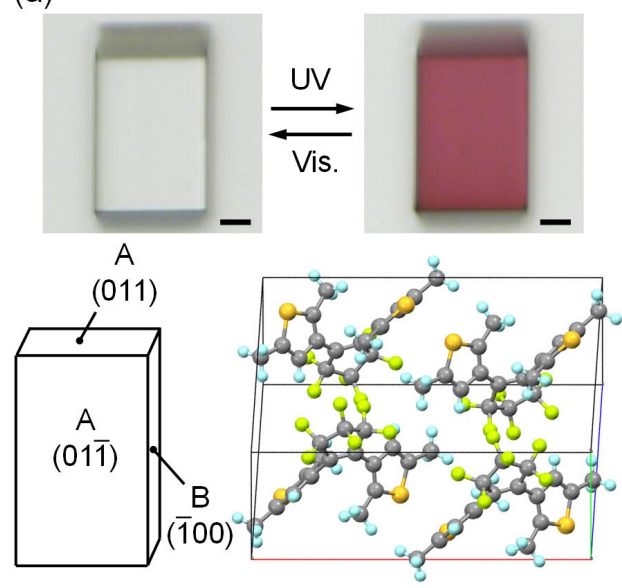

(b)

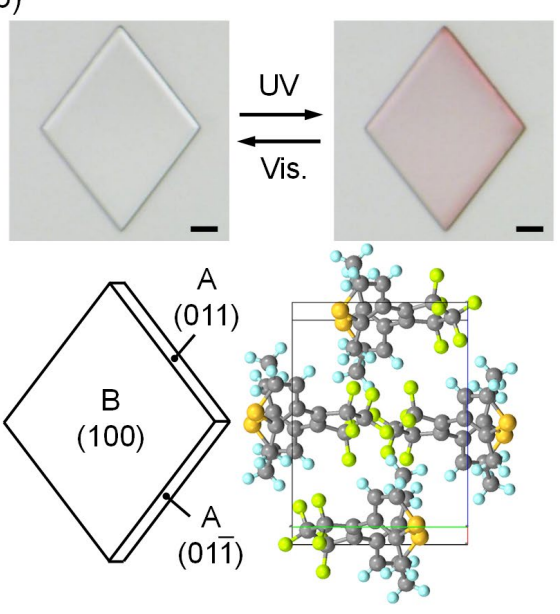

Figure 1. Crystal shape and face indices of crystal 2a and optical microphotographs of single crystals of 2a viewed from (a) Surface A (thickness: $20.7 \mu \mathrm{m}$ ) and (b) Surface B (thickness: $4.6 \mu \mathrm{m}$ ), and their molecular packings viewed from the flat faces. The scale bar is $10 \mu \mathrm{m}$.

When the single crystals of 2 a were observed by rotating the sample stage at $45^{\circ}$ from extinction position under crossed Nicols, the both crystals well-developed on Surfaces A and B exhibited interference colors due to birefringence originated from the refractive index anisotropy in the crystalline phase. To investigate the refractive index anisotropies of crystal $\mathbf{2 a}$ on both surfaces and ascertain the magnitude of the refractive index in two orthogonal directions, crystal 2a was observed 
using a sensitive-tint plate and a 1/4 wavelength plate as shown in Figures 2 and 3, which is the same method reported previously. ${ }^{33}$ In the case of Surface A observed using the sensitive-tint plate under crossed Nicols, the color of the crystal at $+45^{\circ}$ and $-45^{\circ}$ from extinction position was yellow and green, respectively. When the 1/4 wavelength plate was used instead of the sensitive-tint plate, the color of the crystal at $+45^{\circ}$ and $-45^{\circ}$ was bluish-green and pale red, respectively. This means that the refractive index in the direction shown by $n_{1}$ is larger than that in the direction shown by $n_{2}$ in Figure $2 n$. On the other hand, when the sensitive-tint plate was used on Surface B, the color at $+45^{\circ}$ and $-45^{\circ}$ from extinction position was blue and orange, respectively. With the $1 / 4$ wavelength plate, the color of the crystal at $+45^{\circ}$ became darker. This indicates that the refractive index in the direction shown by $n_{1}$ is larger than that in the direction shown by $n_{2}$ in Figure $3 n$. From these results, the retardation $(R)$ of the crystals without any plate was estimated to be approximately 870 and $80 \mathrm{~nm}$ for Surfaces A (thickness: $5.1 \mu \mathrm{m}$ ) and B (thickness: $2.0 \mu \mathrm{m}$ ), respectively. The $R$ values depend on the crystal thickness $(d)$, whereas birefringence $(\Delta n)$ defined by $R / d$ is constant independent of the crystal thickness on the same surface. However, because the accurate $\Delta n$ values have a wavelength dispersion, they can be determined by measuring the transmittance spectrum as shown later.

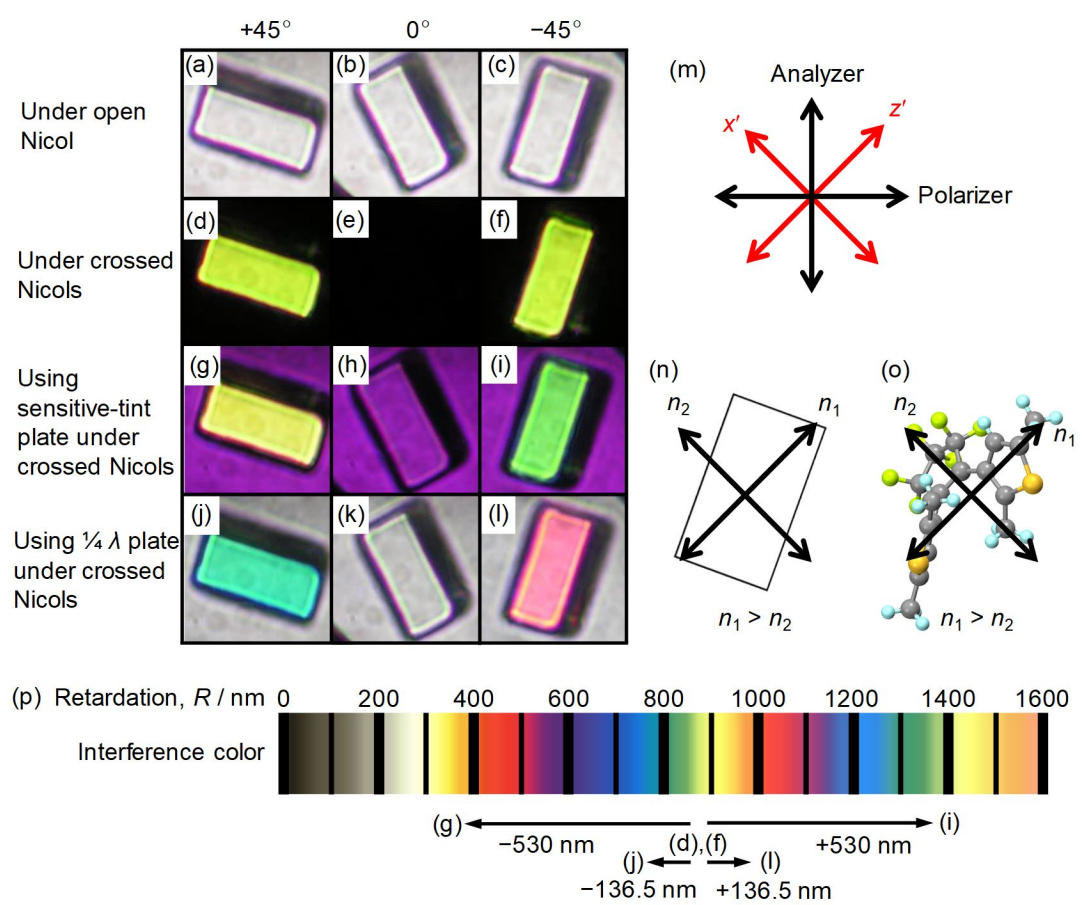


Figure 2. (a-1) Photographs under open Nicol, under crossed Nicols, and through a sensitive-tint plate and a $1 / 4$ wavelength plate at $+45^{\circ}, 0^{\circ}$, and $-45^{\circ}$ from extinction position, $(\mathrm{m})$ the direction of polarizer and analyzer and the direction of $x^{\prime}$ and $z^{\prime}$ for the sensitive-tint and 1/4 wavelength plates, (n) refractive index anisotropy, (o) corresponding crystal packing diagram in crystal 2a on Surface A (thickness: $5.1 \mu \mathrm{m}$ ), and (p) Michel-Lévy color chart.

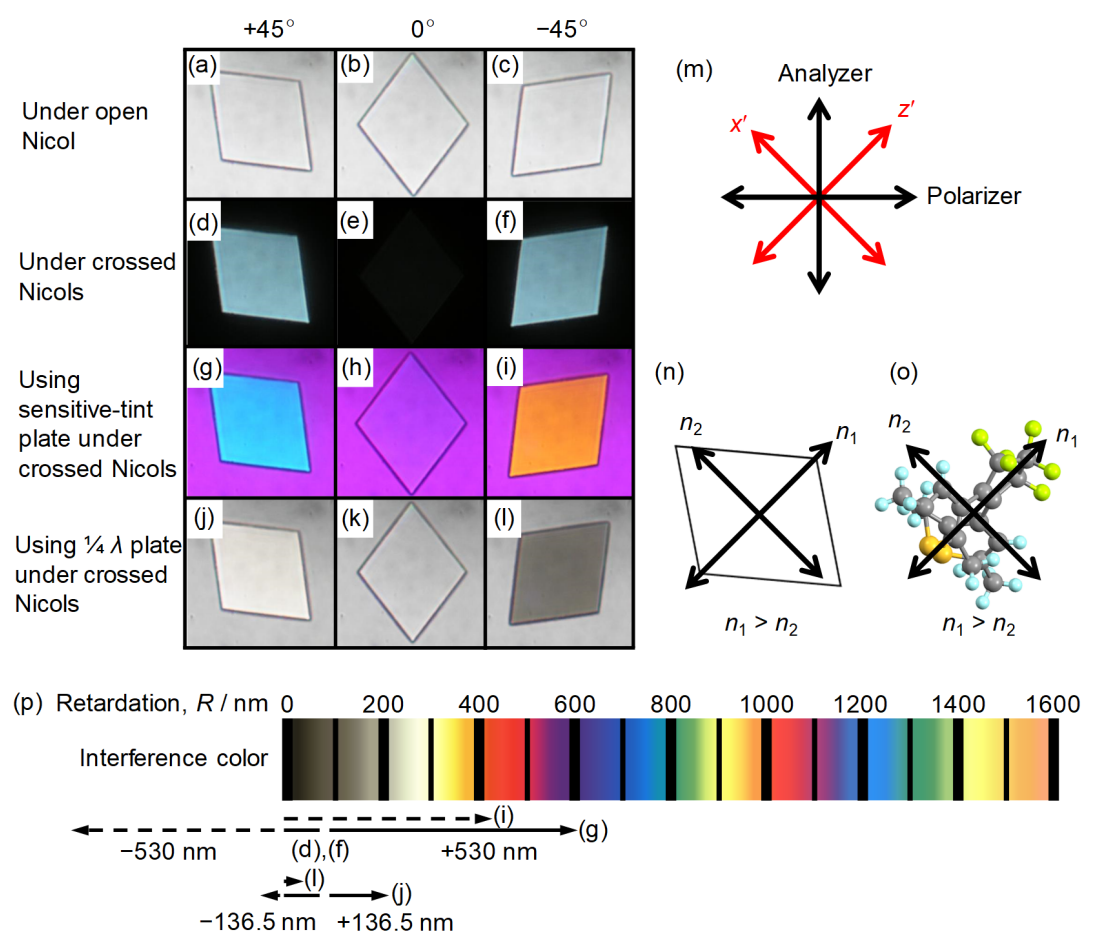

Figure 3. (a-l) Photographs under open Nicol, under crossed Nicols, and through a sensitive-tint plate and a $1 / 4$ wavelength plate at $+45^{\circ}, 0^{\circ}$, and $-45^{\circ}$ from extinction position, $(\mathrm{m})$ the direction of polarizer and analyzer and the direction of $x^{\prime}$ and $z^{\prime}$ for the sensitive-tint and 1/4 wavelength plates, (n) refractive index anisotropy, (o) corresponding crystal packing diagram in crystal $\mathbf{2 a}$ on Surface B (thickness: $2.0 \mu \mathrm{m}$ ), and (p) Michel-Lévy color chart.

Next, the change in interference color of the crystals accompanying the photocyclization reaction upon irradiation with UV light was examined without any plate. Surface A of crystal 2a with a thickness of $3.4 \mu \mathrm{m}$ was used for the experiment. Upon irradiation with UV light, the interference color changed from violet to blue, green, yellow, and orange. The actual color of the crystal observed under open Nicol hardly changed (i.e., the color changed from colorless to pale red), as shown in Figure $4 \mathrm{~b}$. The interference colors were thermally stable at room temperature even after UV 
irradiation was turned off. These results indicate that birefringence could be modulated by the photochromic reaction and the interference color change is quite sensitive to the photochromic reaction. Moreover, on Surface B (thickness: $14.5 \mu \mathrm{m}$ ), the interference color changed from purple to blue and sky blue as shown in Figure 4c. Figure 4d shows the interference color chart with respect to the change in retardation. From the correlation between the color chart and the interference color change, it was revealed that the retardation for $\mathbf{2 a}$ on both Surfaces A and B increased upon UV irradiation.

(a)

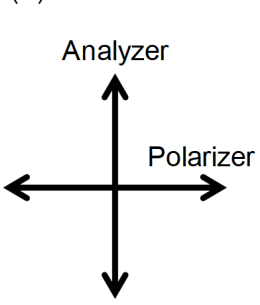

(b)

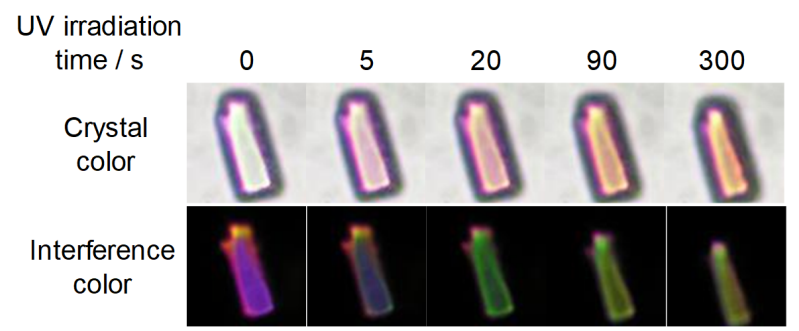

(c)

UV irradiation
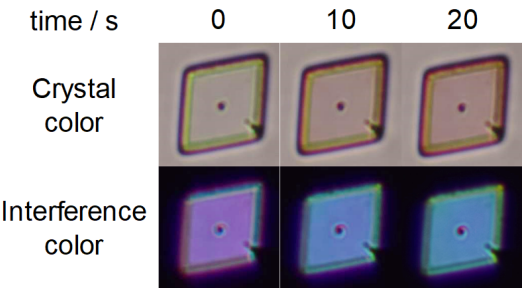

(d) Retardation, $R / \mathrm{nm}$ Interference color
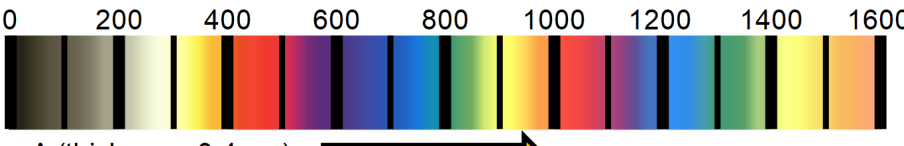

Surface A (thickness: $3.4 \mu \mathrm{m}$ ) Surface B (thickness: $14.5 \mu \mathrm{m}$ )

Figure 4. (a) The direction of polarizer and analyzer, (b) change in crystal color (under open Nicol) and interference color (under crossed Nicols) according to photocyclization reaction of crystal 2a on Surface A $(5 \mu \mathrm{m} \times 18 \mu \mathrm{m}$, thickness: $3.4 \mu \mathrm{m})$ by irradiation with $365 \mathrm{~nm}$ light (Irradiation power: $0.4 \mathrm{~mW} \mathrm{~cm}^{-2}$ ), (c) change in crystal color (under open Nicol) and interference color (under crossed Nicols) according to photocyclization reaction of crystal 2a on Surface B (20 $\mu \mathrm{m} \times 20 \mu \mathrm{m}$, thickness: $14.5 \mu \mathrm{m}$ ) by irradiation with $365 \mathrm{~nm}$ light (Irradiation power: $1.1 \mathrm{~mW} \mathrm{~cm}^{-2}$ ), and (d) Michel-Lévy color chart.

To quantitatively estimate the value of retardation from the interference color, the transmittance spectra of the crystal were examined. Figure 5 shows the transmittance spectra of the crystals observed by rotating at $45^{\circ}$ from the extinction position under crossed Nicols. Before photoirradiation, the transmittance spectra exhibited clear interference curves due to birefringence. Upon irradiation with UV light, the transmittance spectrum on both surfaces of crystal 2a was shifted to longer 
wavelength. The resultant transmittance spectrum was used for fitting to theoretical formulas shown in eqs 1 and 2. Eq 1 is given as an expression representing the light intensity $(I)$ transmitted through the birefringent material under crossed Nicols. ${ }^{35}$

$$
\begin{aligned}
I & =I_{0} \sin ^{2}(\pi R / \lambda) \\
& =I_{0} \sin ^{2}(\pi d \Delta n / \lambda)
\end{aligned}
$$

where $I_{0}$ is the transmitted intensity without the crystal from halogen lamp under parallel Nicols, $R$ is retardation, $\lambda$ is the wavelength of the light, $\Delta n$ is birefringence, and $d$ is the thickness of the crystal. Note that it is necessary to consider the wavelength dispersion of birefringence. Eq 2 represents the wavelength dispersion of birefringence, which is known as a Sellmeier-type equation. ${ }^{36}$

$$
\Delta n=A+\frac{B}{\lambda^{2}-C}
$$

where $A, B$, and $C$ are coefficients. The details to estimate the value of birefringence are depicted in Figures S1 and S2, and the results are shown in Tables S1 and S2.

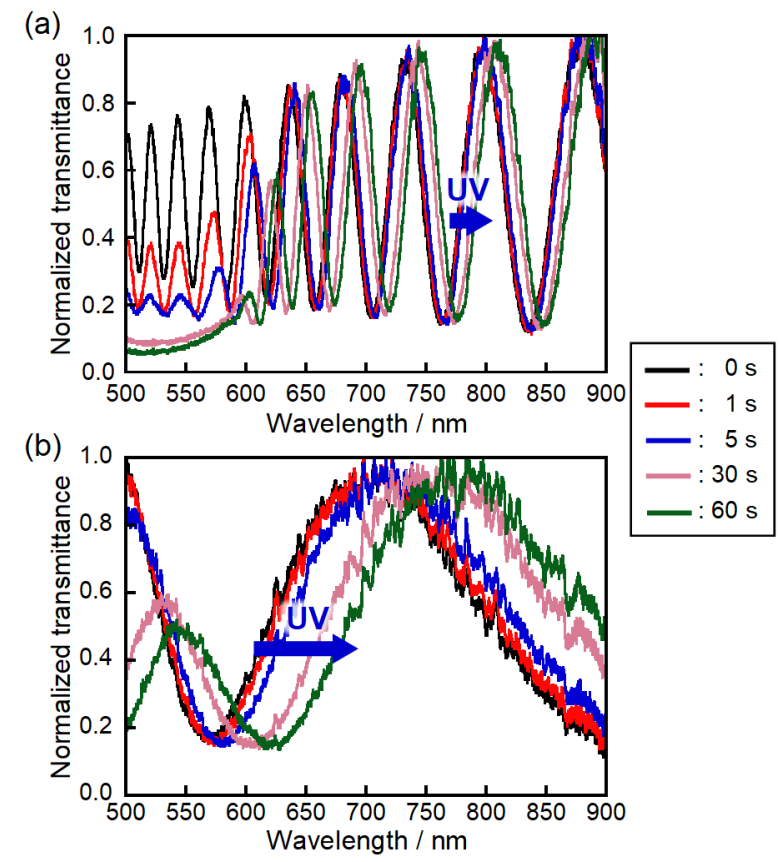


Figure 5. Transmittance spectra for (a) Surface A (thickness: $50.4 \mu \mathrm{m}$ ) and (b) Surface B (thickness: $29.1 \mu \mathrm{m}$ ) of crystal $2 \mathrm{a}$ observed by rotating at $45^{\circ}$ from extinction position under crossed Nicols. The power of UVirradiation with $365 \mathrm{~nm}$ light was $4 \mathrm{~mW} \mathrm{~cm}^{-2}$.

Figure 6 shows the initial $R$ and $\Delta n$ values obtained by fitting for surface A (thickness: $50.4 \mu \mathrm{m}$ ) and surface B (thickness: $29.1 \mu \mathrm{m}$ ) of crystal 2a. The value of $\Delta n$ on surface A was larger than that on surface B. This is because the tilt of the long and short axis of the diarylethene molecule against the observed crystal face was different between surface A and surface B. These findings are clarified by the molecular polarizability determined by quantum chemical calculations in the later section. After UV irradiation, the birefringence is changed by the photochromic reaction as described above. In order to ignore the effect of the linear dichroism, the $R$ and $\Delta n$ values were determined in the wavelength region $(\lambda=650-900 \mathrm{~nm})$ where $\mathbf{2 b}$ has no absorption. ${ }^{37}$ The $R$ and $\Delta n$ values of crystal $\mathbf{2 a}$ on both Surfaces A and B along with the photochromic reaction from $\mathbf{2 a}$ to $\mathbf{2} \mathbf{b}$ were estimated as shown in Figure 7. The $R$ values increased on both surfaces. Thus, the $\Delta n$ values increased on both surfaces. These are consistent with the results of the change in the interference color described above.

The reversibility of birefringence by the reversible photochromic reactions was examined. Figure 8a shows the reversible transmittance spectral change on Surface A of crystal 2a upon alternating irradiation with UV and visible light. When the reversibility of the transmittance change was observed at $665 \mathrm{~nm}$, the reversible birefringence change was confirmed more than 5 cycles without any damage, as shown in Figure $8 \mathrm{~b}$. Figures $8 \mathrm{c}$ and d also show the reversibility of the photoinduced birefringence change on Surface B. Such reversibility is one of the advantages for the use of diarylethene derivatives with high durability character. 


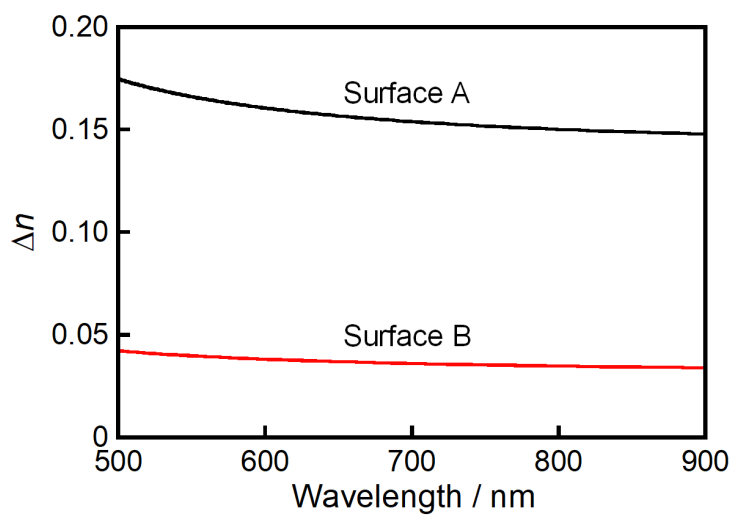

Figure 6. Initial birefringence values on both surfaces of crystal 2a.
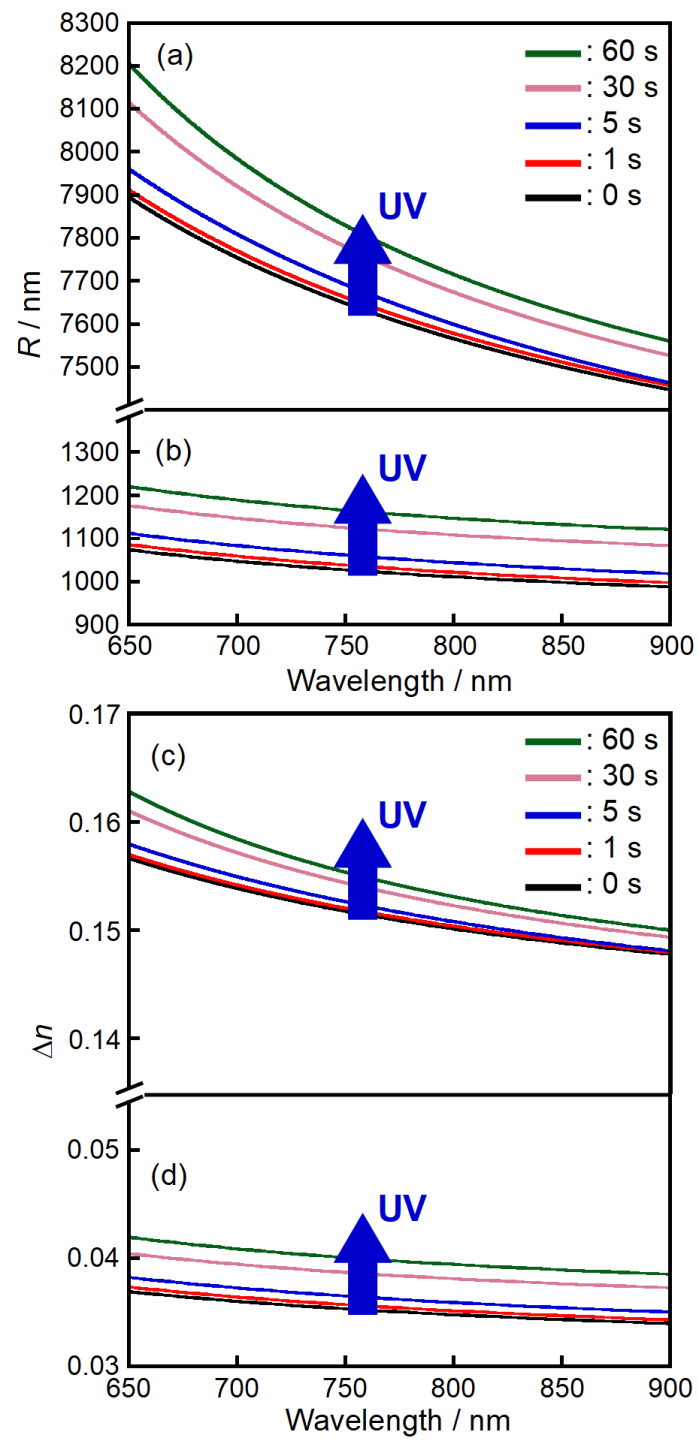
Figure 7. $R$ and $\Delta n$ values at each UV irradiation time determined by fitting for (a, c) Surface A (thickness: $50.4 \mu \mathrm{m}$ ) and (b, d) Surface B (thickness: $29.1 \mu \mathrm{m}$ ) of crystal 2a. The power of UV irradiation with $365 \mathrm{~nm}$ light was $4 \mathrm{~mW} \mathrm{~cm}^{-2}$.
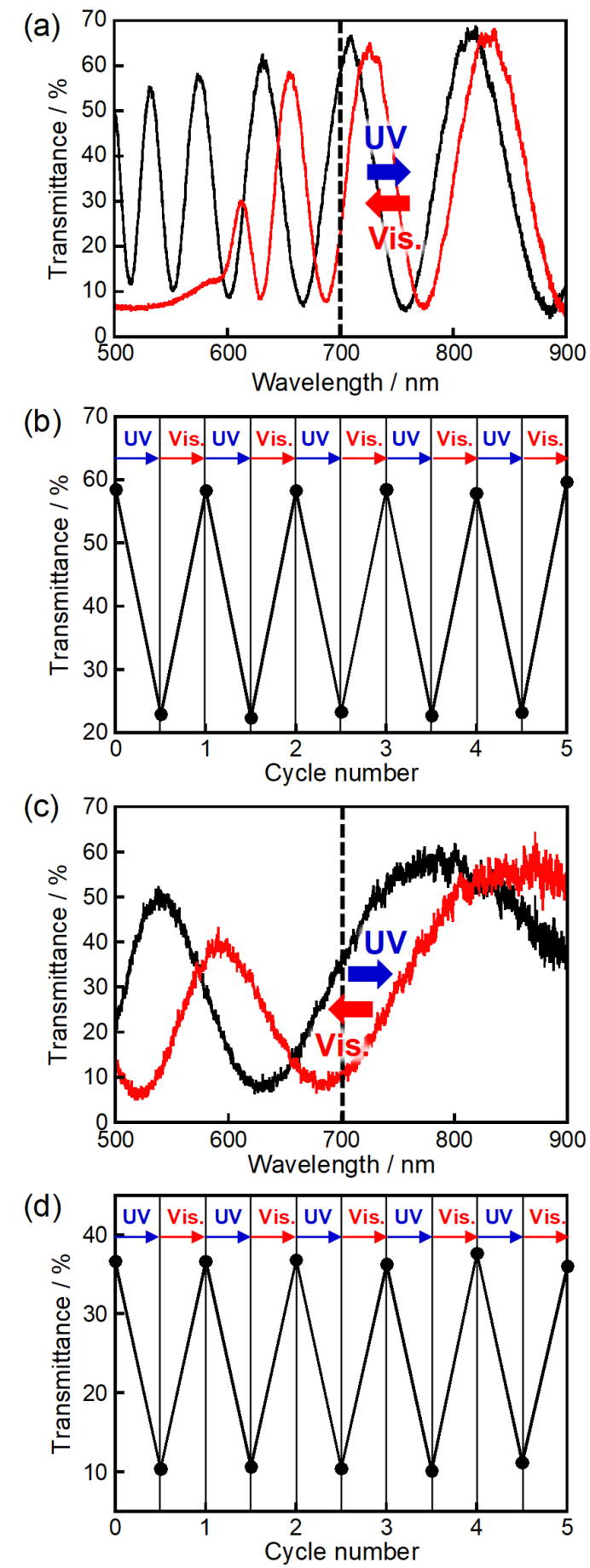

Figure 8. Photoreversible change in transmittance spectrum on Surfaces (a) A (thickness: $29.3 \mu \mathrm{m}$ ) and (c) B (thickness: $34.9 \mu \mathrm{m}$ ) of crystal 2a upon alternating irradiation with $365 \mathrm{~nm}$ light (power: $100 \mathrm{~mW} \mathrm{~cm}^{-2}$ ) for (a) $1 \mathrm{~s}$ and (c) $5 \mathrm{~s}$ and visible light, and (b, d) the repeatability for transmittance observed at $700 \mathrm{~nm}$. 
Relationship between Birefringence Change and Molecular Structure. The question is why the interference color could be modulated by the photochromic reaction. One may think that it is due to a change in the thickness of the crystal upon photoirradiation (i.e., Photomechanical effect of the crystals upon photoirradiation). However, in the present case, the crystal thickness hardly changed because the conversion ratio from the open-ring isomer to the closed-ring isomer is quite low. ${ }^{33}$ Here, we assume that it is due to the change in the molecular polarizability anisotropy. It is well known that there is a relationship between polarizability and refractive index as Lorentz-Lorenz equation (eq 3 ). ${ }^{38}$

$$
\left(\frac{n^{2}-1}{n^{2}+2}\right)\left(\frac{M}{\rho}\right)=\frac{4}{3} \pi N \alpha
$$

where $n$ is a refractive index, $\rho$ is density, $M$ is molecular weight, $N$ is Avogadro constant, and $\alpha$ is polarizability. Eq 3 can be rearranged to eq 4 that represents the relationship between birefringence and molecular polarizability anisotropy. ${ }^{38}$

$$
\Delta n=\frac{2}{9} \pi \frac{\left(n^{2}+2\right)^{2}}{n} \frac{\rho N}{M} \Delta \alpha
$$

where $\Delta \alpha$ is the molecular polarizability anisotropy (i.e., the difference in the molecular polarizability between two axes in the molecule; $\left.\Delta \alpha=\left|\alpha_{1}-\alpha_{2}\right|\right)$. Eq 4 shows that the $\Delta n$ is directly proportional to the molecular polarizability anisotropy $\Delta \alpha$. To estimate $\Delta \alpha$, we calculated the molecular polarizability tensor $(\alpha)$ by a quantum chemical calculation. Note that the molecular structures of the photogenerated closed-ring forms $\mathbf{1 b}$ and $\mathbf{2 b}$ in the crystals $\mathbf{1 a}$ and $\mathbf{2 a}$ were used for the calculation, which could be obtained as disordered components in the X-ray crystallographic analysis as shown in Figure S3. ${ }^{34,39,40}$ In $\mathbf{1 b}$, only the reactive carbon and sulfur atoms appear as disordered components. In contrast, all atoms in $\mathbf{2 b}$ appear as disordered components. When the conversion ratio from the open-ring form to the closed-ring form in the crystal becomes high, the phenyl group in $\mathbf{1 b}$ may rotate 
differently from the dihedral angle between phenyl and thiophene rings in the open-ring form. ${ }^{41}$ However, in this study, since the conversion ratio in the crystal is low, we assumed that all atoms except the reactive carbon and sulfur atoms are the same as those of $\mathbf{1 a}$.

The molecular structures, the axes of the output file $(\boldsymbol{x}, \boldsymbol{y}$, and $\boldsymbol{z})$, and the polarizability tensor in the output files of the calculations are summarized in Figure 9 and Table 1. The quantum chemical calculation provides the molecular polarizability tensors $(\alpha)$ that are not diagonalized as shown in eq 5, which is difficult to handle as it is. Here, the polarizability ellipsoid was introduced. Generally, refractive index anisotropy is presented as the refractive ellipsoid. ${ }^{42}$ The intersection of the index ellipsoid with the observed plane is an ellipse and the refractive index ( $n_{1}$ and $\left.n_{2}\right)$ can be obtained from the lengths of the semi-axes of the ellipse. Moreover, molecules are regularly aligned in crystal, and the refractive index is expressed as the sum of the polarizability. ${ }^{43}$ Accordingly, the molecular polarizability anisotropy ( $\alpha_{1}$ and $\alpha_{2}$ ) can be estimated by depicting the polarizability ellipsoid similar to the refractive index ellipsoid. ${ }^{44}$ To depict the polarizability ellipsoid, diagonalization of the polarizability tensors as shown in eq 6 is required. The eigenvectors $(\boldsymbol{s}, \boldsymbol{k}$, and $\boldsymbol{t})$ and the eigenvalues $\left(\alpha_{\mathrm{s}}, \alpha_{\mathrm{k}}\right.$, and $\left.\alpha_{\mathrm{t}}\right)$ indicate the ellipsoid axes (the principal axes) and the lengths of the semi-axes of the ellipsoid (principal values), respectively.

$$
\begin{gathered}
\boldsymbol{\alpha}=\left(\begin{array}{ccc}
\alpha_{x x} & \alpha_{x y} & \alpha_{x z} \\
\alpha_{y x} & \alpha_{y y} & \alpha_{y z} \\
\alpha_{z x} & \alpha_{z y} & a_{z z}
\end{array}\right) \\
\left(\alpha_{x y}=\alpha_{y x}, \alpha_{x z}=\alpha_{z x}, \alpha_{z y}=\alpha_{y z}\right)
\end{gathered}
$$

After diagonalization,

$$
\boldsymbol{\alpha}=\left(\begin{array}{lll}
\boldsymbol{s} & \boldsymbol{k} & \boldsymbol{t}
\end{array}\right)\left(\begin{array}{ccc}
\alpha_{s} & 0 & 0 \\
0 & \alpha_{k} & 0 \\
0 & 0 & a_{t}
\end{array}\right)\left(\begin{array}{lll}
\boldsymbol{s} & \boldsymbol{k} & \boldsymbol{t}
\end{array}\right)^{-1}
$$

The vectors and values determined in this work are summarized in Table 2. The relationship between the principal axes and their molecular structures are also shown in Figure 9. As can be seen 
from the figure, the ellipsoid axes mostly correspond to the molecular axes. All of the principal values for the long axes of diarylethene were largest. In the case of diarylethene 1a, when the molecule was isomerized from $\mathbf{1 a}$ to $\mathbf{1 b}$, the polarizability in the long axis direction of the molecule $\left(\alpha_{\mathrm{s}}\right)$ largely increased from 513.166 to 834.944 , and the polarizability in the short axis direction of the molecular $\left(\alpha_{\mathrm{k}}\right)$ and the thickness direction of the molecule $\left(\alpha_{\mathrm{t}}\right)$ slightly increased from 256.573 to 293.284 and from 242.583 to 254.897 , respectively. This is because the conjugation length was changed by photocyclization, which had the most influence on the long axis direction of the diarylethene. In the case of diarylethene $\mathbf{2 a}$, when the molecule was isomerized from $\mathbf{2 a}$ to $\mathbf{2} \mathbf{b}$, the polarizability in the direction of the long and short axes of the molecule $\left(\alpha_{\mathrm{s}}\right.$ and $\left.\alpha_{\mathrm{k}}\right)$ increased from 261.369 to 299.572 and from 200.573 to 224.417 , respectively, while the polarizability in the thickness direction of the molecule $\left(\alpha_{\mathrm{t}}\right)$ decreased from 142.194 to 123.959 . The increase of the polarizability can be explained by the same reason as diarylethene 1a. Regarding the decrease of the polarizability, this is because the molecular spatial spread of the open-ring isomer was larger than those of the closed-ring isomer.

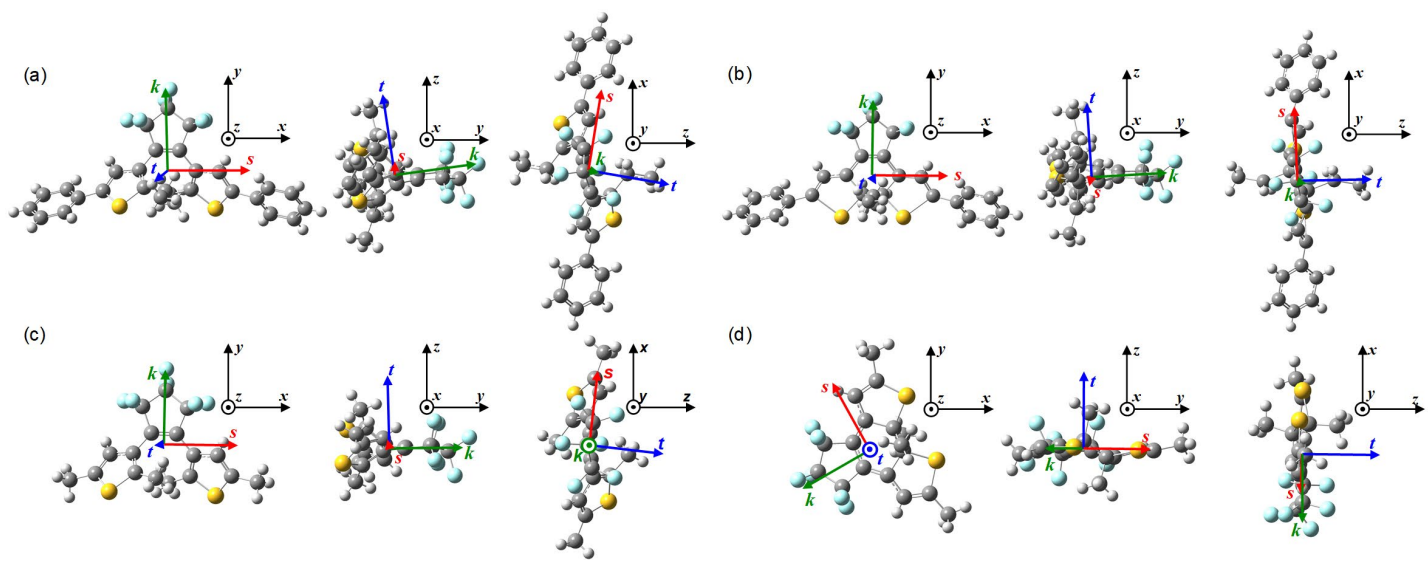

Figure 9. The molecular structures and the axes of the output file $(\boldsymbol{x}, \boldsymbol{y}$, and $\boldsymbol{z})$ in the output files of the calculations for (a) 1a, (b) $\mathbf{1 b}$, (c) $\mathbf{2 a}$, (d) $\mathbf{2 b}$. The axes $(\boldsymbol{s}, \boldsymbol{k}$, and $\boldsymbol{t})$ indicated the principal axes of molecular polarizability ellipsoid. 
Table 1. Polarizability (a.u.) in the output files of the calculations. ${ }^{a}$

\begin{tabular}{ccccccc} 
& $\alpha_{x x}$ & $\alpha_{x y}$ & $\alpha_{y y}$ & $\alpha_{x z}$ & $\alpha_{y z}$ & $\alpha_{z z}$ \\
\hline $\mathbf{1 a}$ & 505.966 & 0.235 & 256.287 & 43.369 & 2.048 & 250.019 \\
$\mathbf{1 b}$ & 834.334 & -2.357 & 293.122 & -18.627 & 2.652 & 255.669 \\
$\mathbf{2 a}$ & 259.628 & -1.478 & 200.573 & 14.178 & 1.133 & 143.935 \\
$\mathbf{2 b}$ & 242.372 & -32.038 & 281.583 & 1.243 & -2.095 & 123.993 \\
\hline
\end{tabular}

${ }^{\text {a }} 1$ a.u. $=1.649 \times 10^{-41} \mathrm{C}^{2} \mathrm{~m}^{2} \mathrm{~J}^{-1}$

Table 2. The principal axes and the principal values (a.u.) of polarizability ellipsoid. ${ }^{\text {a }}$

\begin{tabular}{|c|c|c|c|c|c|c|}
\hline & $\alpha_{\mathrm{s}}$ & $s$ & $\alpha_{\mathrm{k}}$ & $\boldsymbol{k}$ & $\alpha_{\mathrm{t}}$ & $t$ \\
\hline & & 0.987 & & -0.025 & & -0.161 \\
\hline \multirow[t]{3}{*}{$1 \mathbf{a}$} & 513.166 & 0.002 & 256.573 & 0.990 & 242.583 & -0.143 \\
\hline & & 0.163 & & 0.141 & & 0.977 \\
\hline & & 0.999 & & 0.007 & & 0.032 \\
\hline \multirow[t]{3}{*}{$1 b$} & 834.944 & -0.005 & 293.284 & 0.998 & 254.897 & -0.067 \\
\hline & & -0.032 & & 0.067 & & 0.997 \\
\hline & & 0.993 & & 0.019 & & -0.120 \\
\hline \multirow[t]{3}{*}{$2 \mathbf{a}$} & 261.369 & -0.022 & 200.573 & 1.000 & 142.194 & -0.022 \\
\hline & & 0.120 & & 0.025 & & 0.993 \\
\hline & & -0.489 & & -0.872 & & -0.007 \\
\hline \multirow[t]{2}{*}{$2 b$} & 299.572 & 0.872 & 224.417 & -0.489 & 123.959 & 0.012 \\
\hline & & -0.014 & & -0.001 & & 1.000 \\
\hline
\end{tabular}

${ }^{\text {a }} 1$ a.u. $=1.649 \times 10^{-41} \mathrm{C}^{2} \mathrm{~m}^{2} \mathrm{~J}^{-1}$ 
(a)

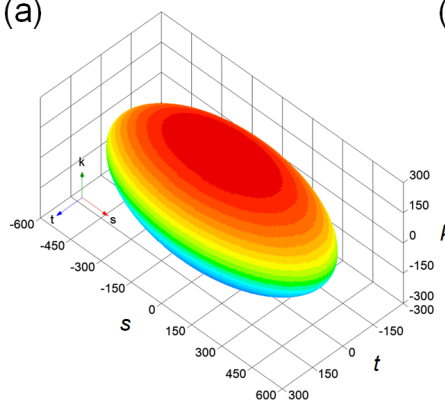

(c)

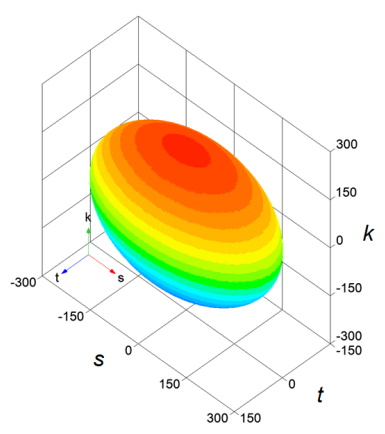

(b)

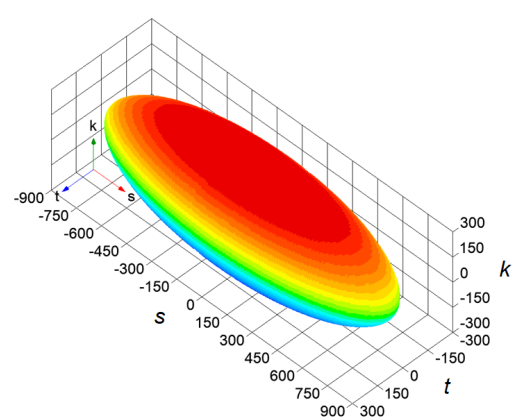

(d)

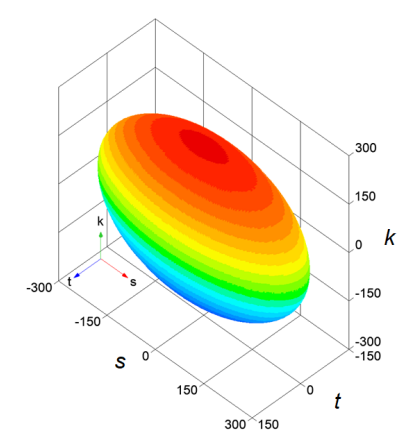

Figure 10. Polarizability ellipsoid of (a) 1a, (b) 1b, (c) 2a, and (d) $\mathbf{2 b}$.

Moreover, the molecular polarizability ellipsoids were depicted in Figure 10. The intersection of the index ellipsoid with the plane viewed from the observed crystal surface was determined to estimate the polarizability anisotropy $\left(\alpha_{1}\right.$ and $\left.\alpha_{2}\right)$. The plane was calculated by rotating the polarizability ellipsoid by an arbitrary angle using a rotation matrix. Figure 11 shows the molecular structures for the open-ring isomers (1a and $\mathbf{2 a})$ and the closed-ring isomers (1) and $\mathbf{2 b})$, the axes of the molecular polarizability, and the ellipse considering the observed crystal surface. As the determined axes of the molecular polarizability were almost matched with the experimental optical axes as shown in Figures 2 and 3, the values of $\alpha_{1}$ and $\alpha_{2}$ in each molecule were determined from the intersection of the ellipse with the experimental optical axes and summarized in Table 3. The molecular polarizabilities in $\mathbf{1 a}$ and $\mathbf{1 b}$ are larger than those in $\mathbf{2 a}$ and $\mathbf{2 b}$, respectively. This is due to the $\pi$-conjugation by a phenyl group. From the molecular polarizability ellipsoid, we can also explain the dependence of the initial birefringence values in crystal 2a on Surfaces A and B. As shown in Table 3, the $\Delta \alpha$ value for $\mathbf{2 a}$ on Surface B is 44 , which is smaller than the value on Surface A $(\Delta \alpha=$ 96). This is consistent with the experimental result that $\Delta n$ on Surface $\mathrm{A}$ is larger than that on Surface B. Depending on the direction of the observation, the ellipse shapes and the polarizability values were 
different. Furthermore, the molecular polarizability should change in proportional to the conversion ratio from the open-ring isomer to the closed-ring isomer. Then, the relationship between the molecular polarizability and the conversion ratio from the open-ring isomer to the closed-ring isomer was depicted as shown in Figure 12. The change in width between two straight lines directly means the difference in $\Delta \alpha$ by the photochromic reaction. Note that the conversion ratio from the open-ring form to the closed-ring form is quite low (less than 10\%). In the case of diarylethene 1a, $\Delta \alpha$ decreases with the conversion ratio from $\mathbf{1 a}$ to $\mathbf{1 b}$, while, for diarylethene $\mathbf{2 a}, \Delta \alpha$ increases with the conversion ratio from $\mathbf{2 a}$ to $\mathbf{2 b}$. These results mean that the $\Delta n$ for $\mathbf{1 a}$ and $\mathbf{2 a}$ decreases and increases respectively, which is consistent with the results we observed. Thus, the relationship between the photoinduced birefringence change of crystals 1a and 2a and their molecular structures can be successfully explained based on the molecular polarizability anisotropy.

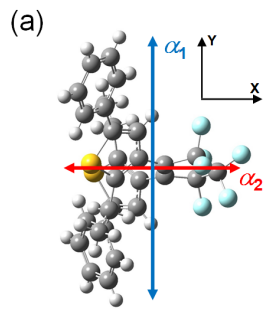

(c)

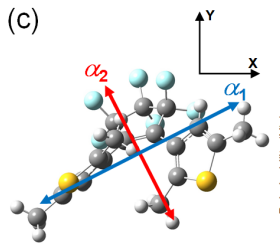

(e)
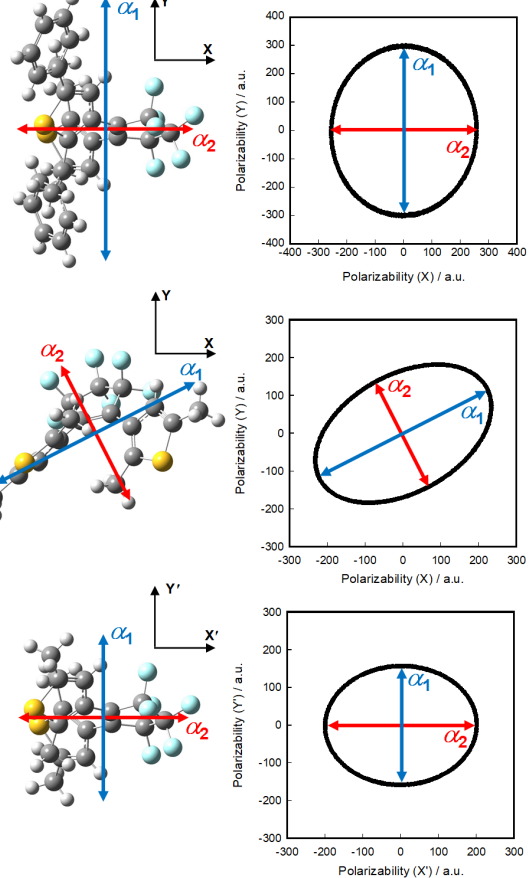

Polarizability $(X) /$ a.u

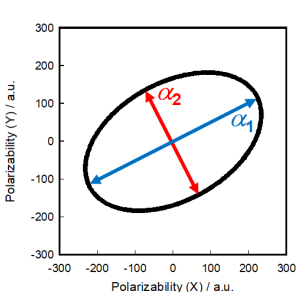

(b)

(d)
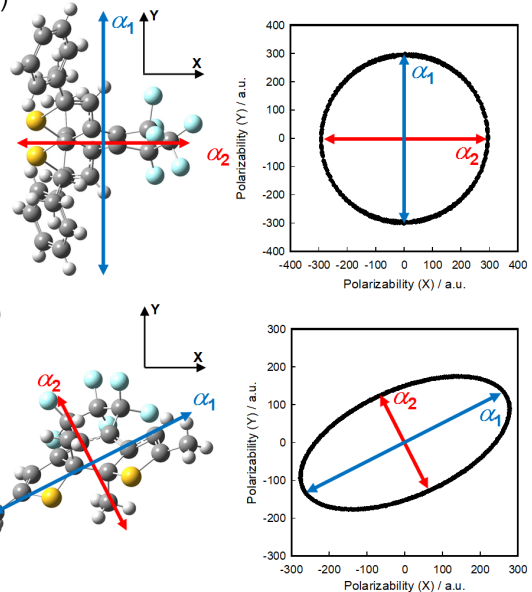

(f)
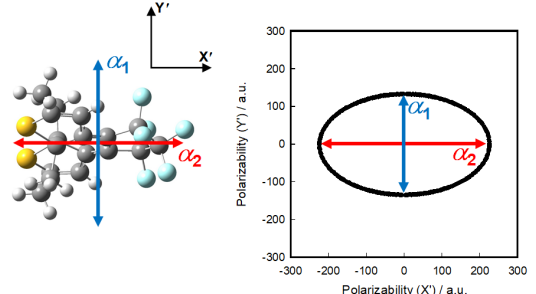

Figure 11. The molecular structures for the open-ring isomers and the closed-ring isomers, the axes of the molecular polarizability, and the ellipse considering the observation on the crystal surface for (a) 1a, (b) 1b, (c) 2a (Surface A), (d) 2b (Surface A), (e) 2a (Surface B), and (f) $2 \mathbf{b}$ (Surface B). 
Table 3. Calculated polarizability (a.u.) in crystal packing. ${ }^{\text {a }}$

\begin{tabular}{cccc}
\hline & $\alpha_{1}$ & $\alpha_{2}$ & $\Delta \alpha$ \\
\hline $\mathbf{1 a}$ & 298 & 256 & 42 \\
$\mathbf{1 b}$ & 296 & 293 & 3 \\
$\mathbf{2 a}($ Surface A) & 251 & 155 & 96 \\
$\mathbf{2 b}($ Surface A) & 294 & 142 & 152 \\
$\mathbf{2 a}($ Surface B) & 157 & 201 & 44 \\
$\mathbf{2 b}($ Surface B) & 134 & 225 & 91 \\
\hline
\end{tabular}

${ }^{\text {a }} 1$ a.u. $=1.649 \times 10^{-41} \mathrm{C}^{2} \mathrm{~m}^{2} \mathrm{~J}^{-1}, \Delta \alpha=\left|\alpha_{1}-\alpha_{2}\right|$.
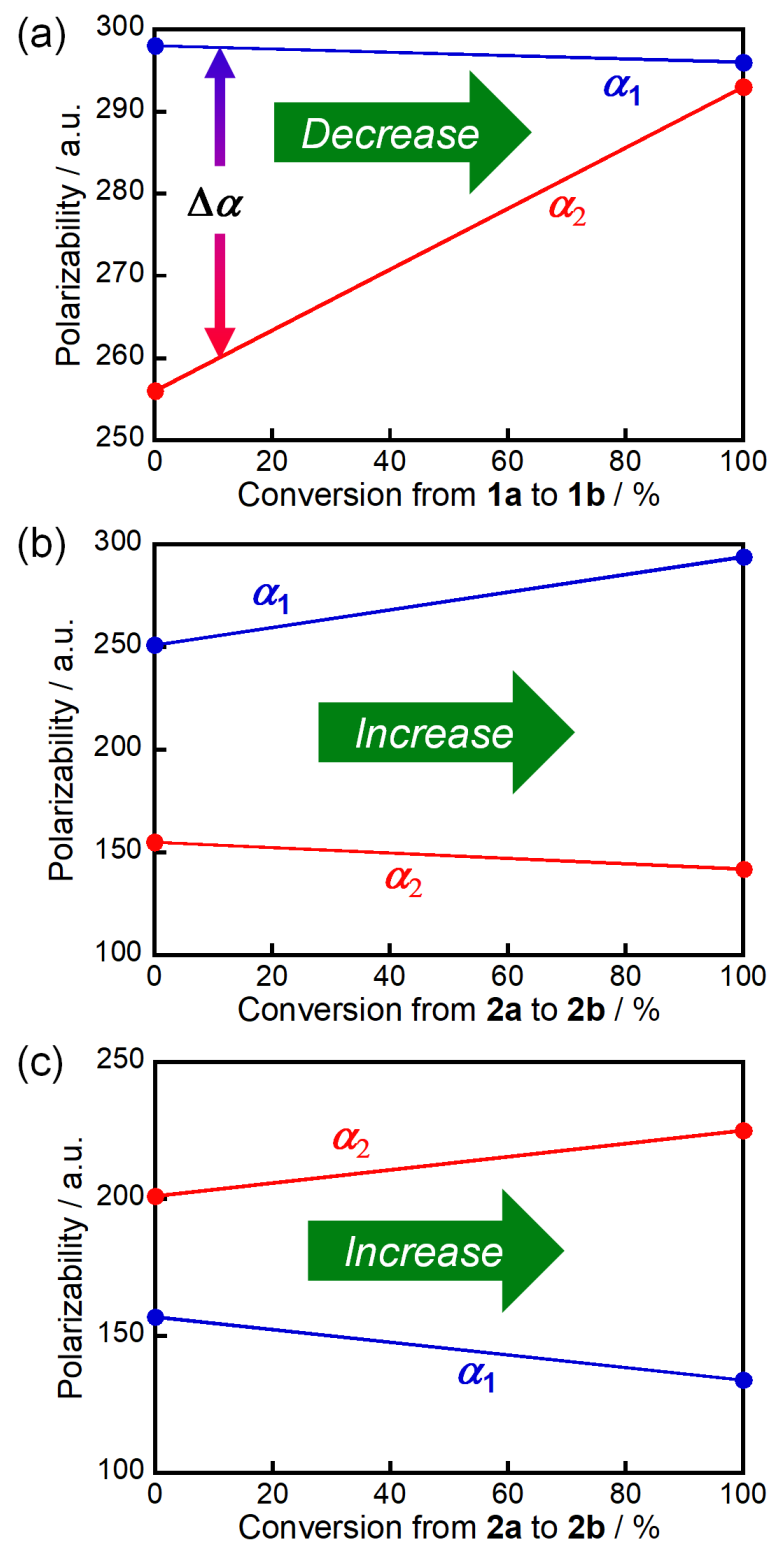
Figure 12. Relationship between the molecular polarizability and the conversion ratio from the openring isomer to the closed-ring isomer for (a) 1, (b) 2 on Surface A, and (c) 2 on Surface B.

\section{Conclusions}

We have prepared the thin single crystals of $\mathbf{2 a}$ and investigated the photoinduced birefringence change by the photochromic reaction. The crystals exhibited photoreversible interference color change originated from birefringence change by the photochromic reaction, which was quite sensitive to the photochromic reaction. The relationship between the birefringence change and molecular structure was revealed in the viewpoint from the molecular polarizability anisotropy estimated by quantum chemical calculations. These results provide not only new opportunities for the application of photochromic crystals but also useful strategies for the design of molecular crystalline materials exhibiting the desired birefringence change.

\section{Experimental Section}

General. Optical microphotographs of crystals were also observed using a Keyence VHX-500 digital microscope and UV irradiation was carried out using a Keyence UV-LED UV-400 (365 nm light). Interference color changes were observed using a Nikon ECLIPSE E600POL polarizing optical microscope, equipped with a video camera system. Crystal thickness was determined using a KEYENCE VK-8700 laser scanning microscope. UV light irradiation to the crystals was carried out using a super high-pressure mercury lamp (100 W; UV-1A filter (365 nm light excitation)) attached to the polarizing optical microscope. Visible light irradiation was carried out using a halogen lamp $(100 \mathrm{~W})$. Transmittance spectra were measured using the polarizing optical microscope connected with an Ocean Optics USB4000 fiber optic spectrometer. Quantum chemical calculation was performed using Gaussian 09 Rev. C.01 program package. ${ }^{45}$ The molecular polarizability was calculated at DFT B3LYP/6-31G(d) level of theory using the coordinates obtained from the X-ray crystal structure analysis previously reported. ${ }^{34,39,40}$ The CCDC numbers of $\mathbf{1 a}, \mathbf{1 b}, \mathbf{2 a}$, and $\mathbf{2 b}$ is $159602,629166,147109$, and 147108, respectively. 
Materials. 1,2-Bis(2,5-dimethyl-3-thienyl)perfluorocyclopentene (2a) was synthesized according to the procedures described in the literature. ${ }^{37}$ The micrometer-size single crystals were prepared by sublimation of the compounds on the glass plates.

Observation of crystals. Optical photographs of crystals were observed with a digital microscope under non-polarized light. To investigate the refractive index anisotropy, the observation was carried out using the sensitive-tint and $1 / 4$ wavelength $(\lambda=546 \mathrm{~nm})$ plates with a polarizing optical microscope under crossed Nicols with polarizer and analyzer being orthogonal. The interference color change accompanying the birefringence change was observed under crossed Nicols. At the same time, change in color tone of the crystal by the photochromic reaction was observed under open Nicol with the removal of the analyzer.

\section{Associated content}

Supporting Information.

Preparation of thin crystal 2a, Determination of the value of birefringence change in crystal 2a, molecular structure used for the quantum chemical calculation, including Tables S1 and S2 and Figures S1-S3 (PDF).

\section{Author information}

\section{Corresponding Author}

* E-mail: kobatake@a-chem.eng.osaka-cu.ac.jp.

\section{Notes}

The authors declare no competing financial interest.

\section{Acknowledgments}

This work was partly supported by JSPS KAKENHI Grant Number JP26107013 in Scientific Research on Innovative Areas "Photosynergetics" to S.K., JSPS KAKENHI Grant Number JP16K17896 in Scientific Research for Young Scientists (B) to D.K. The authors also thank Nippon Zeon Co., Ltd. for providing octafluorocyclopentene. 


\section{References}

(1) Irie, M.; Yokoyama, Y.; Seki, T. New Frontiers in Photochromism; Springer, 2013.

(2) Naumov, P.; Chizhik, S.; Panda, M. K.; Nath, N. K.; Boldyreva, E. Mechanically Responsive Molecular Crystals. Chem. Rev. 2015, 115, 12440-12490.

(3) Koshima, H. Mechanically Responsive Materials for Soft Robotics; Wiley, 2020.

(4) Chi, Z.; Zhang, X.; Xu, B.; Zhou, X.; Ma, C.; Zhang, Y.; Liu, S.; Xu, J. Recent Advances in Organic Mechanofluorochromic Materials. Chem. Soc. Rev. 2012, 41, 3878-3896.

(5) Wenger, O. S. Vapochromism in Organometallic and Coordination Complexes: Chemical Sensors for Volatile Organic Compounds. Chem. Rev. 2013, 113, 3686-3733.

(6) Seki, T.; Ito, H. Molecular-Level Understanding of Structural Changes of Organic Crystals Induced by Macroscopic Mechanical Stimulation. Chem.-Eur. J. 2016, 22, 4322-4329.

(7) Kato, M.; Ito, H.; Hasegawa, M.; Ishii, K. Soft Crystals: Flexible Response Systems with High Structural Order. Chem.-Eur. J. 2019, 25, 5105-5112.

(8) Li, E.; Jie, K.; Liu, M.; Sheng, X.; Zhu, W.; Huang, F. Vapochromic Crystals: Understanding Vapochromism from the Perspective of Crystal Engineering. Chem. Soc. Rev. 2020, 49, 15171544.

(9) Commins, P.; Hara, H.; Naumov, P. Self-Healing Molecular Crystals. Angew. Chem. Int. Ed. 2016, 55, 13028-13032.

(10) Karothu, D. P.; Weston, J.; Desta, I. T.; Naumov, P. Shape-Memory and Self-Healing Effects in Mechanosalient Molecular Crystals. J. Am. Chem. Soc. 2016, 138, 13298-13306.

(11) Zhang, L.; Bailey, J. B.; Subramanian, R. H.; Groisman, A.; Tezcan, F. A. Hyperexpandable, Self-Healing Macromolecular Crystals with Integrated Polymer Networks. Nature 2018, 557, $86-91$.

(12) Commins, P.; Al-Handawi, M. B.; Karothu, D. P.; Raj, G.; Naumov, P. Efficiently SelfHealing Boronic Ester Crystals. Chem. Sci. 2020, 11, 2606-2613.

(13) Schneemann, A.; Bon, V.; Schwedler, I.; Senkovska, I.; Kaskel, S.; Fischer, R. A. Flexible Metal-Organic Frameworks. Chem. Soc. Rev. 2014, 43, 6062-6096. 
(14) Irie, M.; Fukaminato, T.; Matsuda, K.; Kobatake, S. Photochromism of Diarylethene Molecules and Crystals: Memories, Switches, and Actuators. Chem. Rev. 2014, 114, 1217412277.

(15) Fiore, A.; Berger, V.; Rosencher, E.; Bravetti, P.; Nagle, J. Phase Matching Using an Isotropic Nonlinear Optical Material. Nature 1998, 391, 463-466.

(16) Weber, M. F.; Stover, C. A.; Gilbert, L. R.; Nevitt, T. J.; Ouderkirk, A. J. Giant Birefringent Optics in Multilayer Polymer Mirrors. Science 2000, 287, 2451-2456.

(17) Tagaya, A.; Ohkita, H.; Mukoh, M.; Sakaguchi, R.; Koike, Y. Compensation of the Birefringence of a Polymer by a Birefringent Crystal. Science 2003, 301, 812-814.

(18) Collett, E. Field Guide to Polarization; SPIE: Bellingham, 2005.

(19) Flossmann, F.; Schwarz, U. T.; Maier, M.; Dennis, M. R. Polarization Singularities from Unfolding an Optical Vortex through a Birefringent Crystal. Phys. Rev. Lett. 2005, 95, 253901.

(20) Nicholls, L. H.; Rodríguez-Fortuño, F. J.; Nasir, M. E.; Córdova-Castro, R. M.; Olivier, N.; Wurtz, G. A.; Zayats, A. V. Ultrafast Synthesis and Switching of Light Polarization in Nonlinear Anisotropic Metamaterials. Nat. Photonics 2017, 11, 628-633.

(21) Niu, S.; Joe, G.; Zhao, H.; Zhou, Y.; Orvis, T.; Huyan, H.; Salman, J.; Mahalingam, K.; Urwin, B.; Wu, J., et al. Giant Optical Anisotropy in a Quasi-One-Dimensional Crystal. Nat. Photonics 2018, 12, 392-396.

(22) Horie, M.; Sassa, T.; Hashizume, D.; Suzaki, Y.; Osakada, K.; Wada, T. A Crystalline Supramolecular Switch: Controlling the Optical Anisotropy through the Collective Dynamic Motion of Molecules. Angew. Chem. Int. Ed. 2007, 46, 4983-4986.

(23) Horie, M.; Suzaki, Y.; Hashizume, D.; Abe, T.; Wu, T.; Sassa, T.; Hosokai, T.; Osakada, K. Thermally-Induced Phase Transition of Pseudorotaxane Crystals: Changes in Conformation and Interaction of the Molecules and Optical Properties of the Crystals. J. Am. Chem. Soc. 2012, 134, 17932-17944.

(24) Setaka, W.; Yamaguchi, K. Thermal Modulation of Birefringence Observed in a Crystalline Molecular Gyrotop. Proc. Natl. Acad. Sci. 2012, 109, 9271-9275. 
(25) Setaka, W.; Yamaguchi, K. Order-Disorder Transition of Dipolar Rotor in a Crystalline Molecular Gyrotop and Its Optical Change. J. Am. Chem. Soc. 2013, 135, 14560-14563.

(26) Inagaki, Y.; Yamaguchi, K.; Setaka, W. A Crystalline Molecular Gyrotop with Germanium Junctions between a Phenylene Rotor and Alkyl Spokes. RSC Adv. 2014, 4, 58624-58630.

(27) Masuda, T.; Arase, J.; Inagaki, Y.; Kawahata, M.; Yamaguchi, K.; Ohhara, T.; Nakao, A.; Momma, H.; Kwon, E.; Setaka, W. Molecular Gyrotops with a Five-Membered Heteroaromatic Ring: Synthesis, Temperature-Dependent Orientation of Dipolar Rotors inside the Crystal, and Its Birefringence Change. Cryst. Growth Des. 2016, 16, 4392-4401.

(28) Fujiwara, A.; Inagaki, Y.; Momma, H.; Kwon, E.; Yamaguchi, K.; Kanno, M.; Kono, H.; Setaka, W. A Crystalline Molecular Gyrotop with a Biphenylene Dirotor and Its TemperatureDependent Birefringence. CrystEngComm 2017, 19, 6049-6056.

(29) Chung, H.; Dudenko, D.; Zhang, F.; D’Avino, G.; Ruzié, C.; Richard, A.; Schweicher, G.; Cornil, J.; Beljonne, D.; Geerts, Y., et al. Rotator Side Chains Trigger Cooperative Transition for Shape and Function Memory Effect in Organic Semiconductors. Nat. Commun. 2018, 9, 278.

(30) Chung, H.; Ruzié, C.; Geerts, Y.; Diao, Y. Hybrid Mechanism of Nucleation and Cooperative Propagation in a Single-Crystal-to-Single-Crystal Transition of a Molecular Crystal. Cryst. Growth Des. 2018, 18, 4245-4251.

(31) Chung, H.; Chen, S.; Sengar, N.; Davies, D. W.; Garbay, G.; Geerts, Y. H.; Clancy, P.; Diao, Y. Single Atom Substitution Alters the Polymorphic Transition Mechanism in Organic Electronic Crystals. Chem. Mater. 2019, 31, 9115-9126.

(32) Takanabe, A.; Tanaka, M.; Johmoto, K.; Uekusa, H.; Mori, T.; Koshima, H.; Asahi, T. Optical Activity and Optical Anisotropy in Photomechanical Crystals of Chiral Salicylidenephenylethylamines. J. Am. Chem. Soc. 2016, 138, 15066-15077.

(33) Morimoto, K.; Tsujioka, H.; Kitagawa, D.; Kobatake, S. Photoreversible Interference Color Modulation to Multicolor in Photochromic Molecular Crystals. Bull. Chem. Soc. Jpn. 2019, 92, 1299-1304. 
(34) Yamada, T.; Kobatake, S.; Irie, M. X-Ray Crystallographic Study on Single-Crystalline Photochromism of 1,2-Bis(2,5-dimethyl-3-thienyl)perfluorocyclopentene. Bull. Chem. Soc. Jpn. 2000, 73, 2179-2184.

(35) Priimagi, A.; Kaivola, M.; Rodriguez, F. J.; Kauranen, M. Enhanced Photoinduced Birefringence in Polymer-Dye Complexes: Hydrogen Bonding Makes a Difference. Appl. Phys. Lett. 2007, 90, 121103.

(36) Yamaguchi, M.; Okada, K.; Manaf, M. E. A.; Shiroyama, Y.; Iwasaki, T.; Okamoto, K. Extraordinary Wavelength Dispersion of Orientation Birefringence for Cellulose Esters. Macromolecules 2009, 42, 9034-9040.

(37) Kobatake, S.; Yamada, T.; Uchida, K.; Kato, N.; Irie, M. Photochromism of 1,2-Bis(2,5dimethyl-3-thienyl)perfluorocyclopentene in a Single Crystalline Phase. J. Am. Chem. Soc. 1999, 121, 2380-2386.

(38) Uchiyama, A.; Ono, Y.; Ikeda, Y.; Shuto, H.; Yahata, K. Copolycarbonate Optical Films Developed Using Birefringence Dispersion Control. Polym. J. 2012, 44, 995.

(39) Kobatake, S.; Shibata, K.; Uchida, K.; Irie, M. Photochromism of 1,2-Bis(2-ethyl-5-phenyl-3thienyl)perfluorocyclopentene in a Single-Crystalline Phase. Conrotatory Thermal Cycloreversion of the Closed-Ring Isomer. J. Am. Chem. Soc. 2000, 122, 12135-12141.

(40) Kobatake, S.; Takami, S.; Muto, H.; Ishikawa, T.; Irie, M. Rapid and Reversible Shape Changes of Molecular Crystals on Photoirradiation. Nature 2007, 446, 778-781.

(41) Kobatake, S.; Hasegawa, H.; Miyamura, K. High-Convertible Photochromism of a Diarylethene Single Crystal Accompanying the Crystal Shape Deformation. Cryst. Growth Des. 2011, 11, 1223-1229.

(42) Tilley, R. J. Colour and the Optical Properties of Materials; John Wiley \& Sons, 2010.

(43) Doi, M.; Edwards, S. F. The Theory of Polymer Dynamics; Oxford University Press, 1988; Vol. 73.

(44) Shafiee, H.; Tagaya, A.; Koike, Y. Design and Synthesis of a Zero-Photoelastic Birefringence Polymer with a High Glass-Transition Temperature by a Random Copolymerization Method. Polym. J. 2011, 43, 306. 
(45) Frisch, M. J.; Trucks, G. W.; Schlegel, H. B.; Scuseria, G. E.; Robb, M. A.; Cheeseman, J. R.;

Scalmani, G.; Barone, V.; Mennucci, B.; Petersson, G. A., et al. Gaussian 09, Revision C.01, Gaussian, Inc.: Wallingford, 2010. 
Table of Contents (TOC) Graphic
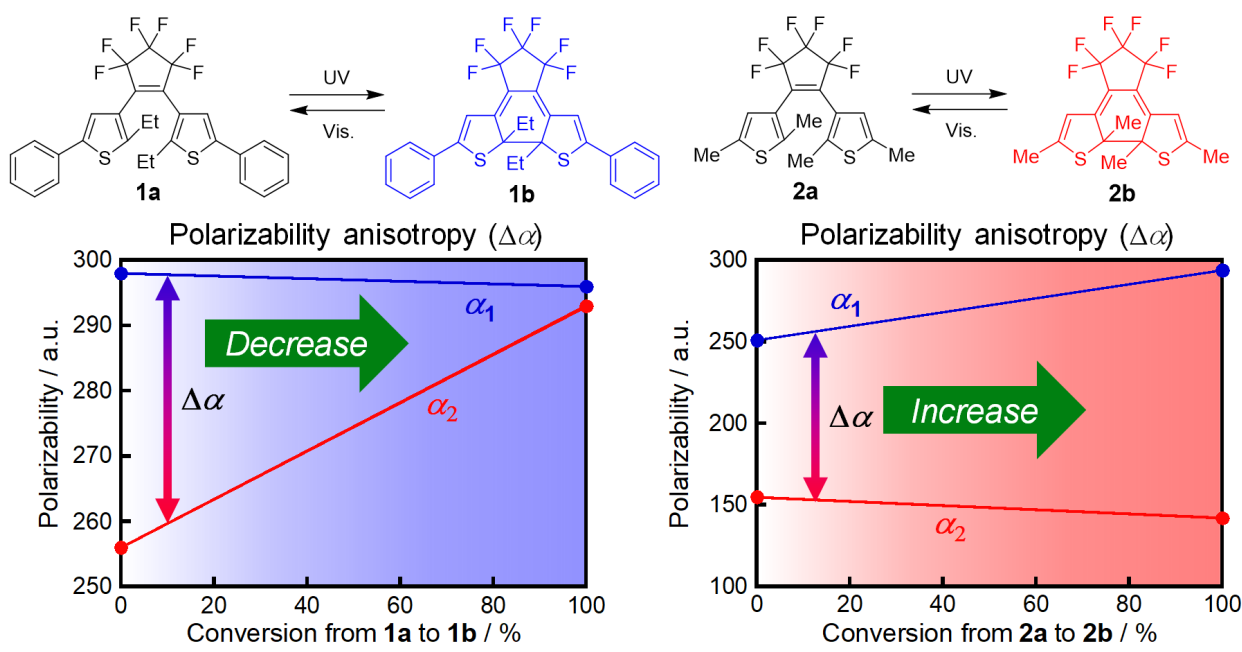